\title{
ERK pathway and sheddases play an essential role in ethanol-induced CX3CL1 release in pancreatic stellate cells
}

\author{
Masahiko Uchida ${ }^{1}$, Tetsuhide Ito ${ }^{1}$, Taichi Nakamura ${ }^{1}$, Hisato Igarashi ${ }^{1}$, Takamasa Oono ${ }^{1}$, Nao Fujimori ${ }^{1}$, \\ Ken Kawabe ${ }^{2}$, Koichi Suzuki ${ }^{3}$, Robert T Jensen ${ }^{4}$ and Ryoichi Takayanagi ${ }^{1}$
}

The clinical course of chronic pancreatitis (CP) worsens with drinking, and pancreatic stellate cells (PSCs) have an important role in the pathogenesis of alcoholic CP. Chemokines recruit inflammatory cells, resulting in chronic pancreatic inflammation. Although serum levels of fractalkine $(C X 3 C L 1)$ are significantly elevated in patients with alcoholic $C P$, the mechanism of this elevation remains unclear. This study aims to determine the effects of cytokines, pathogen-associated molecular patterns (PAMPs), and ethanol and its metabolites on CX3CL1 secretion by PSCs. Male Wistar/Bonn Kobori (WBN/Kob) rats aged 15 to 20 weeks were used as rodent models of CP in vivo. PSCs were isolated from 6-week-old male Wistar rats. The effects of cytokines, PAMPs, and ethanol and its metabolites on chemokine production and activation of signaling pathways in PSCs in vitro were examined by real-time reverse transcription-polymerase chain reaction (RT-PCR), western blotting, and enzyme-linked immunosorbent assay. Expression of CX3CL1 and matrix metalloprotease (MMP)-2 was increased in the pancreas of WBN/Kob rats. The rat PSCs expressed CX3CL1, MMP-2, and a disintegrin and metalloprotease domain (ADAM) 17. Cytokines and PAMPs induced CX3CL1 release and activated extracellular signal-regulated kinase (ERK), MMP-9, and ADAM17. CX3CL1 release was suppressed by specific inhibitors of ERK, MMP, and ADAM, and ERK was associated with CX3CL1 transcription. Ethanol and phorbol myristate acetate synergistically increased CX3CL1 release. Real-time PCR and western blotting confirmed the synergistic activation of ERK and ADAM17. Ethanol synergistically increased CX3CL1 release via ERK and ADAM17 activation in PSCs. In conclusion, we demonstrated for the first time that ethanol synergistically increased CX3CL1 release from PSCs at least in part through activation of ERK mitogen-activated protein kinase and ADAM17. This might be one of the mechanisms of serum CX3CL1 elevation and disease progression in patients with alcoholic CP.

Laboratory Investigation (2013) 93, 41-53; doi:10.1038/labinvest.2012.156; published online 12 November 2012

KEYWORDS: chronic pancreatitis; CX3CL1; ethanol; ERK pathway; pancreatic stellate cells

Chronic pancreatitis $(\mathrm{CP})$ is a progressive fibrotic disease, and the clinical course deteriorates with continued alcohol abuse. ${ }^{1,2}$ Since they were first identified in 1998, pancreatic stellate cells (PSCs) have been recognized as having an important role in the pathogenesis of $\mathrm{CP}^{3,4}$ and are thus considered potential targets for the treatment of the disorder. There are numerous factors involved in the pathogenesis and prolongation of inflammation in $\mathrm{CP}$, including ethanol and acetaldehyde and pathogen-associated molecular patterns (PAMPs) such as bacterial lipopolysaccharide (LPS) and nucleic acids. ${ }^{5-9}$ Cytokines such as interleukin (IL)- $1 \beta$ and platelet-derived growth factor and an autocrine growth factor are also involved in the persistent inflammation, and chemokine secretion from PSCs, which induces inflammatory cell migration into the pancreas, has been recognized as an important factor contributing to the pathogenesis. ${ }^{10-12}$ We have previously shown that in vivo transfection with dominant-negative monocyte chemoattractant protein-1 (MCP-1) vector inhibits progression of $\mathrm{CP}$ in a dibutyltin dichloride $\mathrm{CP}$ rat model, and that the

\footnotetext{
${ }^{1}$ Department of Medicine and Bioregulatory Science, Kyushu University, Fukuoka, Japan; ${ }^{2}$ Department of Kyushu Medical Center, National Hospital Organization, Fukuoka, Japan; ${ }^{3}$ Department of Leprosy Research Center, National Institute of Infectious Diseases, Tokyo, Japan and ${ }^{4}$ Department of Cell Biology Section, NIDDK, National Institutes of Health, Bethesda, MD, USA

Correspondence: Dr T Ito, MD, PhD, Department of Medicine and Bioregulatory Science, Graduate School of Medical Sciences, Kyushu University, 3-1-1 Maidashi, Higashi-ku, Fukuoka 812-8582, Japan.

E-mail: itopapa@intmed3.med.kyushu-u.ac.jp

Received 18 June 2012; revised 30 August 2012; accepted 3 October 2012
} 
chemokine MCP-1 has an important role in disease progression. $^{13}$ Recent studies have also reported that chemokines other than MCP-1 induce inflammation and fibrosis in other organs, and that multiple chemokines are involved in chronic inflammation.

We have focused on the chemokine fractalkine (CX3CL1), which is an adhesion molecule as well as a migration factor and a factor in neuropathic pain. CX3CL1 was discovered in late 1990s. It was identified as a different subclass of the known CX3C chemokines, and so designated as CX3CL1. ${ }^{14-16}$ There are two types of CX3CL1, membrane bound and secretion associated. The extracellular domain is cleaved by a metalloprotease sheddase and secreted in the blood. We have already reported that the serum concentration of CX3CL1 in patients with CP correlates with clinical CP scores and that CX3CL1 is a useful biological marker for early detection of CP because it is secreted in the early stage of the disease. ${ }^{17}$ The concentration of CX3CL1 is increased in chronic drinkers with $\mathrm{CP}$ at any stage of the disease, which suggests that the increase is also associated with alcohol consumption. ${ }^{17}$ Increased expression of CX3CL1 in pancreatic tissue in human CP has also been correlated with pain scores. ${ }^{18}$ As excessive expression and secretion of CX3CL1 has also been observed in patients with rheumatoid arthritis, arteriosclerosis, cardiovascular diseases, HIV infection, nephritis, and neuropathic pain, ${ }^{19-27}$ it has naturally attracted attention as a potential target of treatment for inflammatory diseases. ${ }^{28,29}$

Here, we report new results concerning possible mechanisms of the increase in serum concentrations of CX3CL1, which is associated with fibrosis and pain in patients with alcoholic CP, using culture-activated PSCs.

\section{MATERIALS AND METHODS Animals}

Male Wistar/Bonn Kobori (WBN/Kob) rats commonly develop CP by the age of 3 months and diabetes mellitus by 9 months. ${ }^{30} \mathrm{KOB}$ rats have been widely accepted as a rodent model of CP. In this study, tissues collected from WBN/Kob rats aged 15 to 20 weeks and weighing 180-200g (KBT Oriental, Saga, Japan) were used. All animal procedures were performed in accordance with the guidelines of the Committee on Animal Care of Kyushu University.

\section{Isolation of PSCs and Cell Culture}

PSCs were isolated from the pancreas of the male Wistar rats by density-gradient centrifugation method as previously described. ${ }^{9}$ Purity of PSCs of $>90 \%$ was confirmed by the typical star-like configuration of the cells and by presence of vitamin A autofluorescence. The cells were maintained in complete Dulbecco's modified Eagle medium (DMEM)/F-12, which is a mixture of DMEM and Ham's F-12 nutrient mixture (Wako Pure Chemicals, Osaka, Japan) supplemented with $10 \%$ fetal bovine serum, 50 units $/ \mathrm{ml}$ of penicillin, and $50 \mathrm{mg} / \mathrm{ml}$ of streptomycin (Invitrogen, Carlsbad, CA, USA).
All experiments using PSCs were performed with cells between passages 1 and 4 . Pancreatic acinar cells were isolated from digested pancreas tissue that was pipetted and filtered through a $150-\mu \mathrm{m}$ nylon mesh. Unless otherwise specified, the PSCs were incubated in serum-free medium for $24 \mathrm{~h}$ before experimental reagents were added. In some experiments, specific inhibitors (U0126, batimastat, or TAPI-0) were added $30 \mathrm{~min}$ before the addition of ligands including tumor necrosis factor-alpha $(\mathrm{TNF}-\alpha)$ or polyinosinic-polycytidylic acid with Lipofectamine 2000.

\section{Materials}

Recombinant rat TNF- $\alpha$ and recombinant rat IL- $1 \beta$ were purchased from R\&D systems (Minneapolis, MN, USA). LPS, polyinosinic-polycytidylic acid potassium salt (poly (I:C)), U0126, batimastat, and phorbol myristate acetate (PMA) were obtained from Sigma-Aldrich (St Louis, MO, USA). TAPI-0 was purchased from Santa Cruz Biotechnology (Santa Cruz, CA, USA). Rabbit anti-rat phosphorylated extracellular signal-regulated kinase (ERK) antibody, rabbit anti-rat phosphorylated p38 antibody, and horseradish peroxidase (HRP)-conjugated rabbit anti-rat $\beta$-tubulin antibody were purchased from Cell Signaling Technology (Beverly, MA, USA). Rabbit anti-rat CX3CL1 antibody, rabbit anti-rat matrix metalloprotease (MMP)-2 antibody, rabbit anti-rat disintegrin and metalloprotease domain (ADAM) 17 antibody, rabbit anti-rat MMP-9 antibody, and mouse anti-alpha smooth muscle actin ( $\alpha$-SMA) were purchased from Abcam PLC (Cambridge, UK). Anti-rabbit IgG Alexa 488-conjugated antibody, anti-mouse IgG Alexa 555conjugated antibody, Hoechst 33342, and Lipofectamine2000 were obtained from Invitrogen.

\section{Immunohistochemical Analysis}

Specimens from the body of each pancreas underwent histopathological analysis including hematoxylin-eosin staining, Masson-trichrome staining, and immunostaining for CX3CL1, CX3CR1, and $\alpha$-SMA. Primary antibodies were diluted in phosphate-buffered saline with $2 \%$ bovine serum albumin at 1:100 for CX3CL1 and CX3CR1, and at 1:400 for $\alpha$-SMA.

\section{Expression of Pancreatitis-Related Genes in CP Rats: Real-Time Reverse Transcription-Polymerase Chain Reaction}

Total RNA was extracted from the tail of each pancreas and from the PSCs with an RNeasy mini kit (Qiagen, Valencia, CA, USA) as previously described. ${ }^{31}$ For real-time reverse transcription-polymerase chain reaction (RT-PCR), $100 \mathrm{ng}$ of total RNA was reverse transcribed into first-strand complementary DNA (cDNA) using a PrimeScript RT reagent kit (Takara Bio, Otsu, Shiga, Japan) according to the manufacturer's instructions and RT-PCR was performed using a LightCycler Real-Time PCR system (Roche, Switzerland) according to the manufacturer's instructions. 
The reaction mixture $(20 \mu \mathrm{l})$ contained SYBR Premix Ex Taq II (TLi RNAseH Plus; Takara Bio), $4 \mathrm{~mm} \mathrm{MgCl}_{2}, 0.5 \mathrm{~mm}$ upstream and downstream PCR primers (Table 1), and $2 \mu \mathrm{l}$ of first-strand cDNA template. To control for variations in the reactions, all PCR data were normalized against GAPDH expression.

\section{Immunofluorescence Staining}

Immunofluorescence staining was performed as previously described. ${ }^{9}$ PSCs were serum starved and incubated for $24 \mathrm{~h}$ at $37^{\circ} \mathrm{C}$ and fixed in $4 \%$ paraformaldehyde. After blocking with $2 \%$ normal bovine serum albumin, cells were incubated with rabbit anti-rat CX3CL1, MMP-2, and ADAM17 antibody at 1:100 dilution and with mouse anti-rat $\alpha$-SMA antibody at 1:400 dilution overnight at $4{ }^{\circ} \mathrm{C}$. After washes, cells were incubated with anti-rabbit Alexa 488-conjugated IgG antibody and anti-mouse Alexa 555-conjugated IgG antibody for $1 \mathrm{~h}$. After washes with phosphate-buffered saline, samples were analyzed for fluorescence under a confocal laser scanning microscope (Nikon A1/C1, Tokyo, Japan). Nuclear counterstaining was performed using Hoechst 33342. For a negative control, the primary antibody was replaced with $2 \%$ BSA or polyclonal rabbit IgG (Abcam).

\section{Transfection}

Lipofectamine transfection of nucleic acids was performed as previously described. ${ }^{31}$ Briefly, unless otherwise noted, $10 \mu \mathrm{g}$ of poly (I:C) was mixed with $5 \mu \mathrm{l}$ of Lipofectamine 2000 and $985 \mu \mathrm{l}$ of serum-free medium and incubated for $15 \mathrm{~min}$ at room temperature. A duplicate mixture without poly (I:C) and/or Lipofectamine 2000 was also incubated for $15 \mathrm{~min}$ at room temperature. Combined mixtures, IC $+\mathrm{Tfx}$, were added for RNA transfection.

Table 1 Sequences of primers used in this study

\begin{tabular}{ll}
\hline Gene & Sequence \\
\hline Rat CX3CL1: sense & 5'-CACAAGATGACCTCGCCAAT-3' \\
Anti-sense & 5'-GCTGTCTCGTCTCCAGGATG-3' \\
Rat MMP-2: sense & $5^{\prime}$-ATTGACGGCAAGGACGGA-3' \\
Anti-sense & $5^{\prime}$-CAGTACTCGCCATCAGCGT-3' \\
Rat ADAM17: sense & 5'-GACACTGTGTGCTTGGACC-3' \\
Anti-sense & $5^{\prime}$-CTITGCTCTGCATCGACGT-3' \\
Rat MCP-1: sense & $5^{\prime}$-ACGTGCTGTCTCAGCCAGAT-3' \\
Anti-sense & $5^{\prime}$-GTTCTCCAGCCGACTCATTG-3' \\
Rat MMP-9: sense & $5^{\prime}$-TCGATGACTCCTCGCGCGC-3' \\
Anti-sense & $5^{\prime}$-CTTCGAGCCCGTACACGCGG-3' \\
Rat GAPDH: sense & $5^{\prime}$-GCTCTCTGCTCCTCCCTGTT-3' \\
Anti-sense & $5^{\prime}$-CACACCGACCTCACCATCT-3'
\end{tabular}

\section{Quantification of Soluble CX3CL1 by Enzyme-Linked Immunosorbent Assay}

After $24 \mathrm{~h}$ of incubation, the levels of CX3CL1 in the culture supernatants were measured by enzyme-linked immunosorbent assay (ELISA; Rat CX3CL1 ELISA, RayBiotech, Norcross, GA, USA) according to the manufacturer's instructions. Briefly, $100 \mu \mathrm{l}$ standard or sample was added to each well and then incubated for $2.5 \mathrm{~h}$ at room temperature. After incubation, $100 \mu \mathrm{l}$ prepared biotin antibody was added to each well and incubated for $1 \mathrm{~h}$ at room temperature. After washes, $100 \mu \mathrm{l}$ prepared Streptavidin solution was added to each well and incubated for $45 \mathrm{~min}$ at room temperature. Finally, $100 \mu$ l TMB One-Step Substrate Reagent was added to each well for $30 \mathrm{~min}$ at room temperature, and then $100 \mu \mathrm{l}$ stop reagent was added. Soluble CX3CL1 was quantified by the differences in absorbance at 450 and $520 \mathrm{~nm}$. Calculation of the mean absorbance for each set of duplicate standards, controls, and samples, were performed, and we subtracted the average zero standard optical density.

\section{Quantification of Soluble MCP-1: MCP-1 ELISA}

MCP-1 in culture supernatants after incubation with ligands was also measured by ELISA (Rat MCP-1 ELISA, Thermo Scientific, Rockford, IL, USA) according to the manufacturer's instructions. Briefly, $50 \mu \mathrm{l}$ standard or sample was added to each well and incubated for $1 \mathrm{~h}$ at room temperature. After incubation, $50 \mu \mathrm{l}$ prepared biotin antibody was added to each well and incubated for $1 \mathrm{~h}$ at room temperature. After washes, $100 \mu \mathrm{l}$ prepared Streptavidin solution was added to each well and incubated for $30 \mathrm{~min}$ at room temperature. Finally, $100 \mu \mathrm{l}$ TMB One-Step Substrate Reagent was added to each well for $30 \mathrm{~min}$ at room temperature, and then $100 \mu \mathrm{l}$ stop reagent was added. Soluble MCP-1 was quantified by absorbance at 450 and $520 \mathrm{~nm}$. Calculation of the mean absorbance for each set of duplicate standards, controls, and samples, were performed, and we subtracted the average zero standard optical density.

\section{Western Blotting}

Western blotting was performed as previously described. ${ }^{9}$ Cells were lysed in RIPA buffer (Nacalai Tesque, Kyoto, Japan) and cellular proteins (approximately $50 \mu \mathrm{g}$ ) were fractionated by electrophoresis on a $10 \%$ sodium dodecyl sulfate polyacrylamide gel (Bio-Rad, Hercules, CA, USA). The proteins were transferred to a nitrocellulose membrane (Bio-Rad), and the membrane was incubated for 2 to $6 \mathrm{~h}$ with primary antibodies at 1:1000 dilutions. After incubating with HRP-conjugated anti-rabbit or anti-mouse IgG antibody at 1:10000 dilution, the proteins were visualized with an ECL kit from PerkinElmer (Waltham, MA, USA) and ImageQuant LAS 4000 mini (GE Healthcare Japan Corporation, Tokyo, Japan). Levels of phosphorylated ERK, MMP-2, ADAM17, MMP-9, and $\beta$-tubulin were determined by General-Purpose Analysis Software Multi Gauge (Fujifilm, Tokyo, Japan). 


\section{Statistical Analysis}

Results are expressed as the means (s.e.m.) of 3-4 separate cell preparations per experimental protocol. Two-tailed unpaired Student's $t$-test was used for statistical analyses. $P$-values of $<0.05$ were considered statistically significant.

\section{RESULTS}

\section{PSCs Expressed Sheddases of CX3CL1}

Pancreas from WBN/Kob rats was isolated and examined by immunofluorescence confocal microscopy to evaluate the expression and distribution of CX3CL1 and CX3CR1 in pancreatic tissue. In tissue from CP rats, CX3CL1 expression was observed in acinar cells and in activated $\alpha$-SMA-positive PSCs (arrowhead) in fibrotic tissue (Figure 1a). CX3CR1positive inflammatory cells were also seen in fibrotic stroma (arrow). Next, the expression of sheddases (MMP-2, ADAM17), which is essential to CX3CL1 secretion in the tissues, was quantified by real-time PCR. We found that the in vivo expression of CX3CL1 and sheddases was increased in the rat $\mathrm{CP}$ tissues (Figure 1b). In order to evaluate the possible relationship of these findings with the pathogenesis of $\mathrm{CP}$, we subjected the rat PSCs to immunofluorescence staining and MMP-2 and ADAM17 expression were confirmed in freshly isolated (first) and culture-activated PSCs (third), which suggested the possibility of CX3CL1 secretion (Figure 1c). When the expression of sheddases was compared between acinar cells and PSCs and quantified by real-time PCR, we found that the expression of sheddases was greater in the freshly isolated (first) and culture-activated PSCs (fourth) than in the acinar cells, which suggested that PSCs might be a main source of sheddases in the CP model (Figure 1d). In our experiments, activated PSCs in vitro showed strong expression of sheddases that might induce secretion of CX3CL1 by PSCs and other cells.

\section{Inflammatory Cytokines and PAMPs Induced CX3CL1 Transcription and Secretion in PSCs}

We used real-time PCR and ELISA to determine the effects of cytokines (TNF- $\alpha, 1-100 \mathrm{ng} / \mathrm{ml}$; IL- $1 \beta, 1-100 \mathrm{ng} / \mathrm{ml}$ ) and infectious stimulation (IC $+\mathrm{Tfx}, 0.1-10 \mu \mathrm{g} / \mathrm{ml}$; LPS, $0.1-$ $10 \mu \mathrm{g} / \mathrm{ml})$ on transcription and secretion of CX3CL1 by the rat PSCs. All of these ligands except IC + Tfx had previously been reported to induce CX3CL1 secretion by hepatic stellate cells. We used the IC $+\mathrm{Tfx}$ to imitate viral infection because viral infection has also been reported to be a cause of pancreatitis. $^{32}$ Each of the ligands tested induced transcription of CX3CL1 at $6 \mathrm{~h}$ (Figure 2a) and secretion of soluble CX3CL1 at $24 \mathrm{~h}$ (Figure 2b), which demonstrated that, as with MCP-1, there are numerous potential triggers for transcription and secretion of CX3CL1.

\section{Inflammatory Cytokines and PAMPs Activated ERK Mitogen-Activated Protein Kinase and Sheddases}

Downstream signaling activation caused by inflammatory cytokines and PAMPs was also examined by western blotting and real-time PCR, which were used to detect phosphorylated ERK mitogen-activated protein kinase (MAPK), p38 MAPK, and sheddases. ERK and p38 phosphorylation were induced by TNF- $\alpha$ and IC + Tfx, and the activity peaked between 5 and $15 \mathrm{~min}$ (Figure 3a). No increase in MMP-2 was noted after $6 \mathrm{~h}$. Expression of ADAM17 and MMP-9 were increased at the transcriptional level (Figure $3 \mathrm{~b}$ ).

\section{ERK MAPK and Sheddases had an Essential Role in CX3CL1 Secretion}

We next examined the relationship between activated ERK MAPK, p38 MAPK, sheddases, and CX3CL1 secretion using U0126, an inhibitor of the ERK pathway at $1-10 \mu \mathrm{M}$, and SB203580, an inhibitor of p38 MAPK at $25-100 \mu \mathrm{g} / \mathrm{ml}$. Both of these inhibitors were previously shown to effectively inhibit target pathways in PSCs at the concentrations tested in this study. ${ }^{33}$ We also used batimastat, which is an inhibitor of MMP-2 and MMP-9 at 5-50 $\mu \mathrm{M}$, along with TAPI-0, which inhibits ADAM17 at $0.5-5 \mu \mathrm{g} / \mathrm{ml}$. These agents were also known to inhibit the respective target pathways in hepatic stellate cells at the concentrations used in this study. ${ }^{34}$ In these experiments, for the first time, we obtained a result suggesting that there is a concentration-dependent inhibition of CX3CL1 secretion. This has not been observed with MCP-1. We also found that both sheddases and ERK MAPK were associated with CX3CL1 secretion (Figures 4a-c; Supplementary Figures $\mathrm{S} 1 \mathrm{a}-\mathrm{c})$. There was a slight indication that p38 MAPK was also involved in CX3CL1 secretion in vitro in the rat models tested (data not shown). We identified an important transcriptional pathway by real-time PCR using the same specific inhibitors, determining that batimastat and TAPI-0 did not inhibit transcription, whereas U0126 was strongly inhibitory. Accordingly, we determined that ERK MAPK mainly inhibits transcription of CX3CL1, with the subsequent finding of decreased CX3CL1 secretion

Figure 1 Pancreatic stellate cells (PSCs) expressed fractalkine (CX3CL1) and its sheddases. (a) Expression of CX3CL1 and CX3CR1 in the pancreas of 15 -week-old Wistar Bonn/Kobori (WBN/Kob) rats was examined by immunofluorescence staining. Red shows alpha-smooth muscle actin ( $\alpha$-SMA) expression, whereas green shows CX3CL1 or CX3CR1 expression. Arrowheads indicate CX3CL1-positive PSCs and arrows indicate CX3CR1-positive inflammatory cells. Hematoxylin-eosin (HE) and Masson trichrome staining is also shown. (b) Expression of CX3CL1, matrix metalloprotease (MMP)-2, and a disintegrin and metalloprotease domain (ADAM) 17 in the pancreas of 20-week-old WBN/Kob rats were examined by real-time reverse transcription-polymerase chain reaction (RT-PCR). (c) Expression of CX3CL1, MMP-2, and ADAM17 in freshly isolated (1 day after isolation; first) and culture-activated PSCs (third) was examined by immunofluorescence staining. (d) Total RNA was prepared from dispersed acinar cells (acinar cells), freshly isolated (1 day after isolation; first) and culture-activated PSCs (fourth), and the expression of sheddases was assessed by real-time RT-PCR. $\left({ }^{*} P<0.05,{ }^{*} P<0.01\right)$. 
a
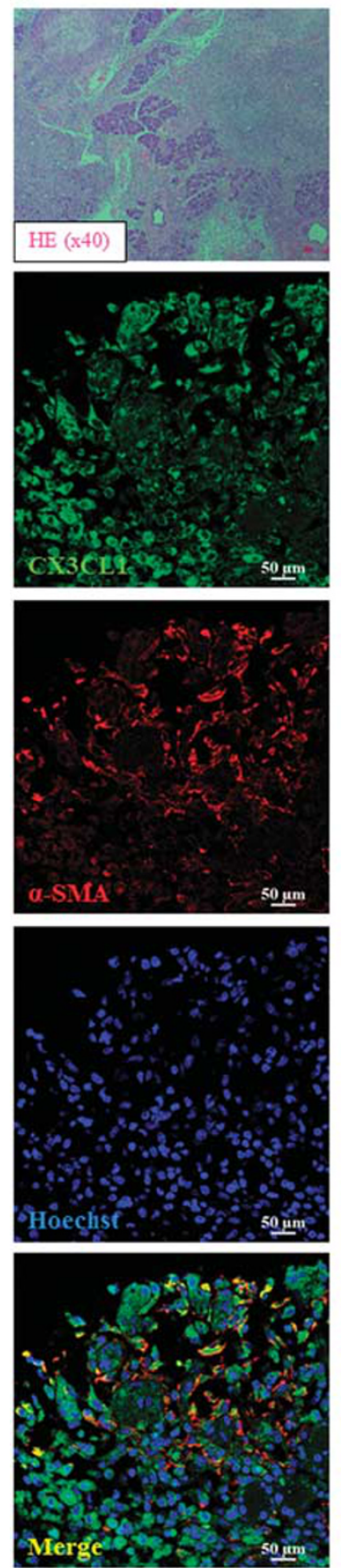

KOB
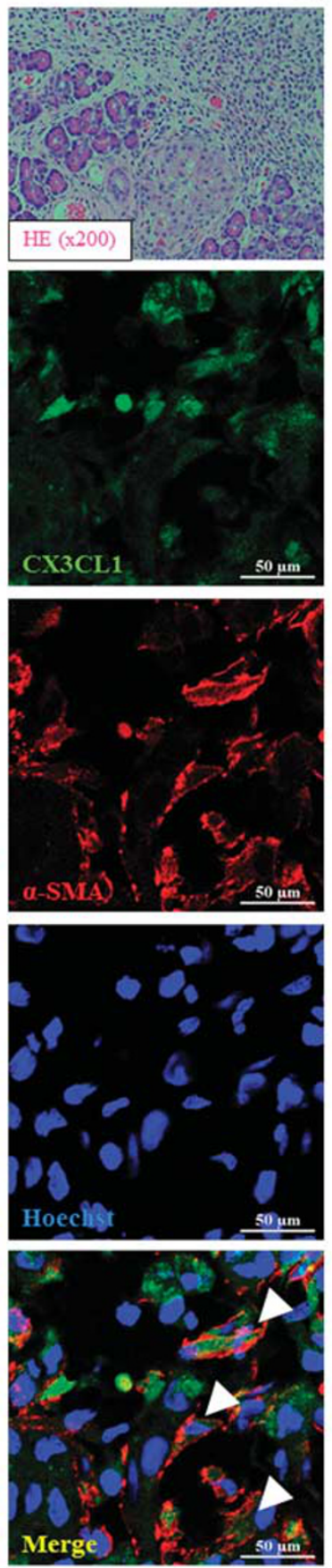
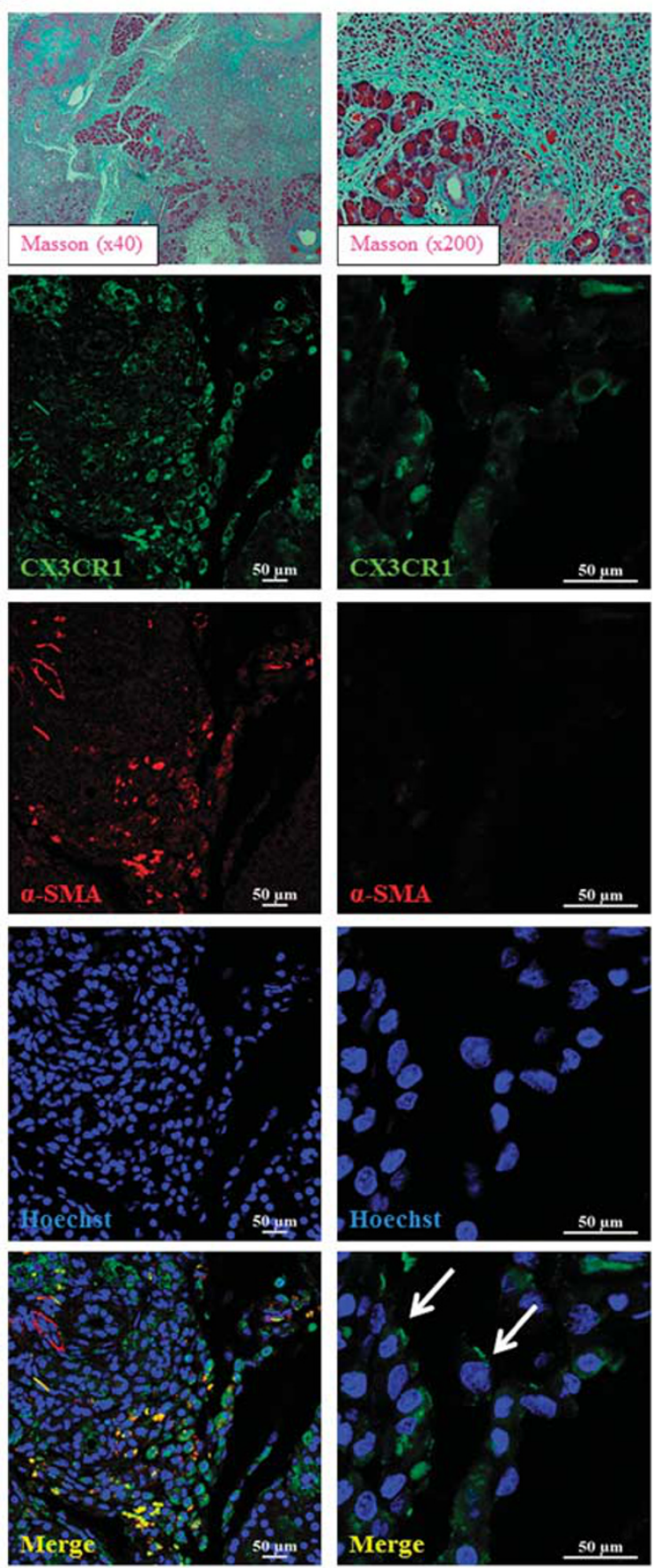

ADAM17
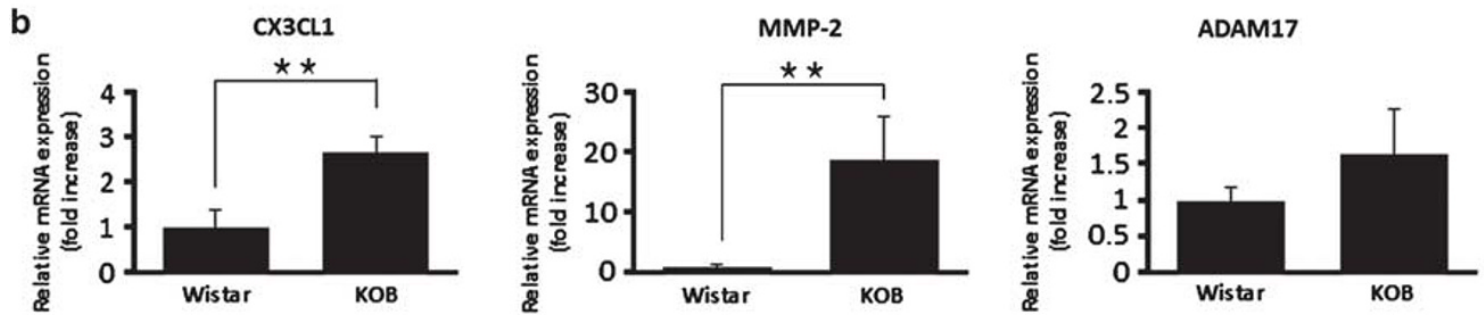
c
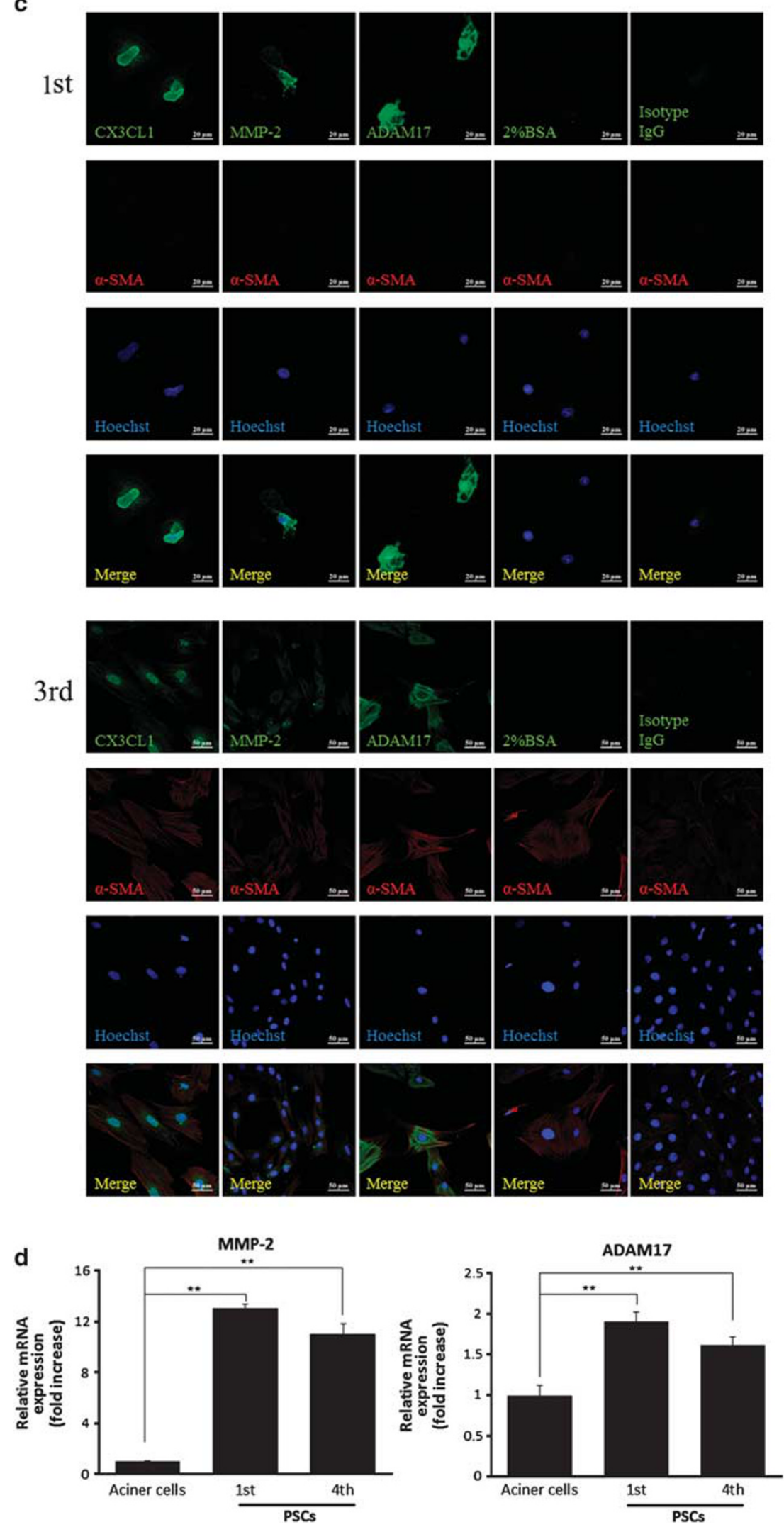

Figure 1 Continued. 
(Figure 4d). MCP-1 transcription was not affected (Supplementary Figure S1d).

\section{Ethanol Synergistically Induced CX3CL1 Release with ERK MAPK and ADAM17 Activation}

We have previously reported that serum levels of CX3CL1 are increased in drinkers with $\mathrm{CP}$, thus, we hypothesized that ethanol and its metabolites promote synergistic acceleration of CX3CL1 release. Ethanol is a substrate of protein kinase C epsilon (PKC $\varepsilon),{ }^{35}$ and we used PMA as a pan-PKC substrate. The synergistic modulatory action of PMA and ethanol and its metabolites on CX3CL1 secretion was evaluated to test our hypothesis. PMA and ethanol showed a modulatory effect on TNF- $\alpha$ mediated CX3CL1 secretion that was not observed with acetaldehyde or palmitic acid ethyl ester (Figures 5a and b, Supplementary Figures S2a and b). Low concentrations of TNF- $\alpha$ (1 or $10 \mathrm{ng} / \mathrm{ml})$ and low concentrations of ethanol (10 or $25 \mathrm{~mm}$ ) also showed synergistic modulatory effects of CX3CL1 secretion (Supplementary Figure S2c). The modulatory action by PMA was also seen in MCP-1, but the action by ethanol was specific to CX3CL1, which suggested that CX3CL1 chemokine action may be induced specifically by ethanol. Real-time PCR was used to determine whether the modulatory action was related to promotion of CX3CL1 gene transcription by ERK activation or transcription by sheddases. Ethanol synergistically promoted transcription of CX3CL1 and ADAM17 in a concentration-dependent manner, and these transcription levels were presumably related to subsequent secretion of the products of the CX3CL1 transcripts (Figures 6a and d, Supplementary Figures S3a and d). As noted, even the low concentration $(10 \mathrm{~mm})$ of ethanol was able to synergistically increase CX3CL1 transcription, but there was no modulatory activation of ethanol observed with MMP-2 or MMP-9 (Figures 6b and c, Supplementary Figures S3b and c). On the other hand, PMA synergistically promoted transcription of CX3CL1, ADAM17, and MMP-9 by TNF- $\alpha$ stimulation, which might represent a different mechanism from that of the modulatory action of ethanol and is probably due to involvement of other PKC isozymes (Figures 6a and d). A pro-MMP-9 protein was also detected after $24 \mathrm{~h}$ stimulation of TNF- $\alpha$ and PMA, which seemed to suggest that MMP-9 is also involved in the modulatory actions on CX3CL1 secretion by TNF- $\alpha$ with PMA (Figure 6e), and we had the same result with poly (I:C) + Tfx (Supplementary Figures S3a-d), so that we were able to conclude that ethanol synergistically
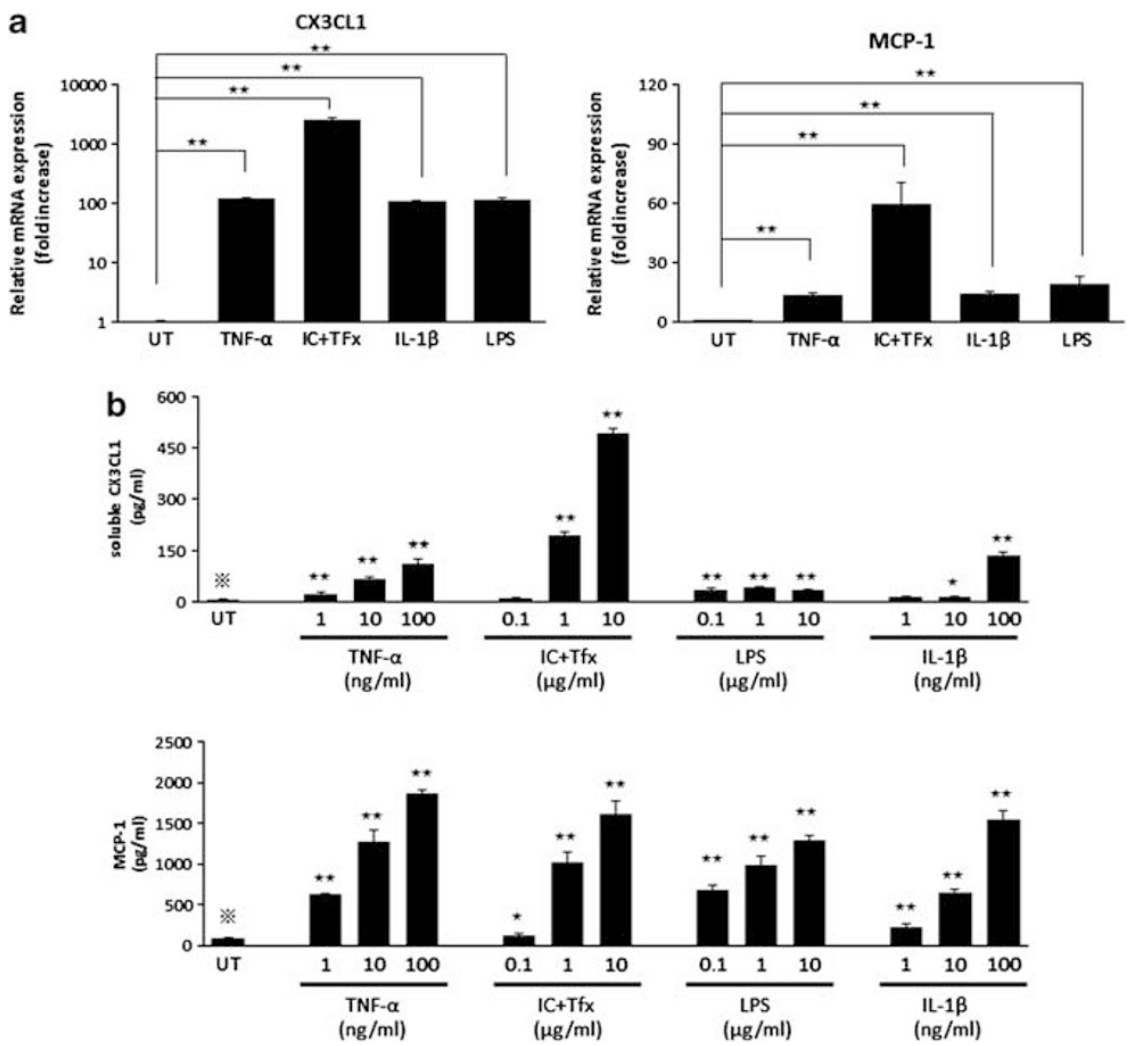

Figure 2 Cytokines and pathogen-associated molecular patterns (PAMPs) induced CX3CL1 gene transcription and soluble CX3CL1 release. Pancreatic stellate cells (PSCs) were left untreated (UT), or were treated with tumor necrosis factor-alpha (TNF- $\alpha, 10 \mathrm{ng} / \mathrm{ml})$, polyinosinic-polycytidylic acid with Lipofectamine 2000 (IC + Tfx, $10 \mu \mathrm{g} / \mathrm{ml}$ ), interleukin-1 beta (IL-1 $\beta, 10 \mathrm{ng} / \mathrm{ml})$, or lipopolysaccharide (LPS, $10 \mu \mathrm{g} / \mathrm{ml})$ for $6 \mathrm{~h}$ (a) or $24 \mathrm{~h}$ (b). (a) Total RNA was prepared from treated or non-treated PSCs and the expression of the CX3CL1 and monocyte chemoattractant protein-1 (MCP-1) genes was assessed by real-time reverse transcription-polymerase chain reaction (RT-PCR). (b) Cell culture supernatants were harvested, and the levels of CX3CL1 and MCP-1 were determined by enzyme-linked immunosorbent assay (ELISA; ${ }^{*} P<0.05,{ }^{* *} P<0.01$ ). 
a
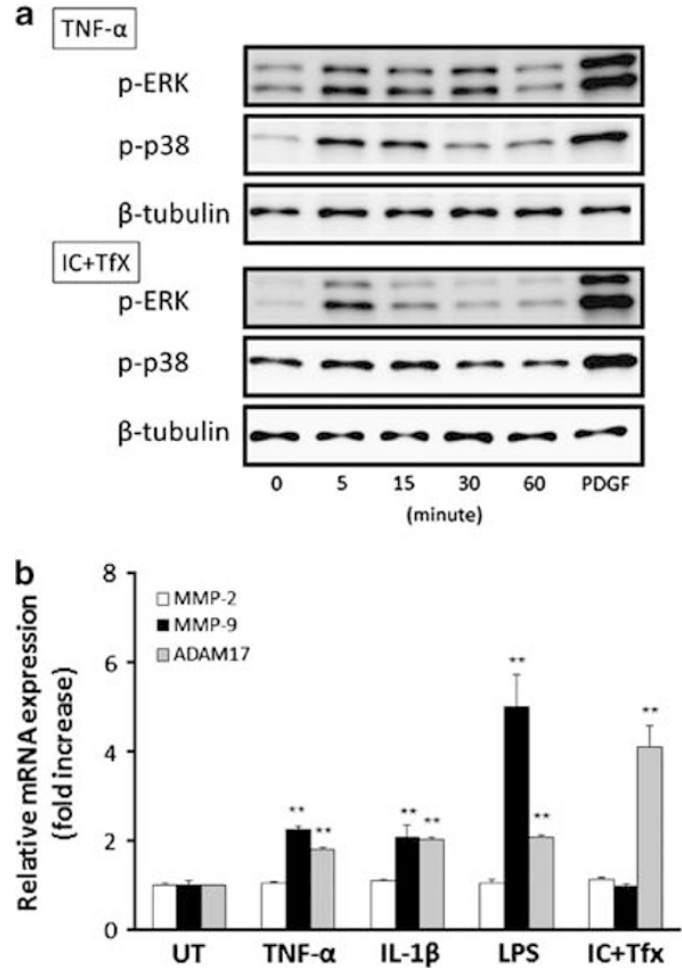

Figure 3 Cytokines and pathogen-associated molecular patterns (PAMPs) activated extracellular signal-regulated kinase (ERK) and sheddases. Pancreatic stellate cells (PSCs) were left untreated (UT), or treated with tumor necrosis factor-alpha (TNF- $\alpha, 10 \mathrm{ng} / \mathrm{ml}$ ), interleukin-1 beta (IL-1 $\beta$, $10 \mathrm{ng} / \mathrm{ml}$ ), lipopolysaccharide (LPS, $10 \mu \mathrm{g} / \mathrm{ml}$ ), or polyinosinic-polycytidylic acid with Lipofectamine 2000 (IC $+\mathrm{Tfx}, 10 \mu \mathrm{g} / \mathrm{ml}$ ), for the indicated time (min) (a) or $6 \mathrm{~h}$ (b). (a) Total cell lysates (approximately $50 \mu \mathrm{g}$ ) were prepared, and the level of phosphorylated-ERK and phosphorylated-p38 was determined by western blotting. (b) Total RNA was prepared from treated PSCs and the expression of the matrix metalloprotease (MMP)-2, MMP-9, and a disintegrin and metalloprotease domain (ADAM) 17 genes was assessed by real-time reverse transcription-polymerase chain reaction (RT-PCR; ${ }^{* *} P<0.01$ vs. each group).

promoted secretion of CX3CL1 via ERK and ADAM17, and that PMA promoted the activation of ERK, ADAM17, and MMP-9 by TNF- $\alpha$ stimulation (Figure 7 ).

\section{DISCUSSION}

It is well known that the pathogenesis of CP is strongly related to alcohol consumption, but the mechanism of the persistent inflammation has yet to be fully elucidated. This study using a rat CP model demonstrated that the expression of CX3CL1 and sheddases was increased and that the main source of the sheddase was PSCs. Furthermore, the study also revealed for the first time that while CX3CL1 secretion, like that of other chemokines, is induced by various inflammatory and infectious stimulants, only the CX3CL1 secretion was synergistically promoted by ethanol. It was postulated that this might be due to activation of ERK MAPK and ADAM17, which are important factors in the progression of alcoholic CP.

Increased CX3CL1 expression in CP tissue was not cell specific. It was observed in acinar cells, the islets of Langerhans, and PSCs, which might contribute to the increase of CX3CL1 expression in the whole CP tissue. This result supported previous study results and indicated that pancreatic tissue injury and various environmental factors promote CX3CL1 expression in the whole pancreas, so that connection of membrane-bound CX3CL1 and CX3CL1 receptors of inflammatory cells in the pancreatic tissue serves as the basis of the inflammation in CP as it does in chronic hepatitis. ${ }^{11,17,18,36,37}$ Furthermore, sheddase is essential for CX3CL1 secretion into the blood. The abundant expression of sheddase in PSCs, as in hepatic stellate cells, ${ }^{34}$ indicates that MMP not only enhances extracellular matrix degradation but also induces inflammation by CX3CL1 secretion. This finding also supports previous study results indicating that not only do PSCs have an important role in extracellular matrix homeostasis, they can also act to trigger inflammation. ${ }^{38,39}$

The finding that CX3CL1 was secreted from PSCs in response to various stimuli suggests that inflammation and infection might promote the progression of CP by chemokine secretion. CX3CL1 provokes the progression of CP by stimulating migration of inflammatory cells such as monocytes and lymphocytes, and it also induces cell proliferation by directly affecting vascular smooth muscle cells and vascular endothelial cells, ${ }^{40-42}$ which suggest that proliferation of PSCs influenced by CX3CL1 may be involved in the pathogenesis of CP. Cytokines including TNF- $\alpha$ and IL- $1 \beta$ and infectious agents such as LPS induce CX3CL1 secretion, and have shown similar effects in vascular smooth muscle cells and hepatic stellate cells. ${ }^{34,43}$ This study has also verified that CX3CL1 secretion was induced by stimulation of cytosolic double-stranded RNA, which suggests that PSCs might have the same mechanism of response to viral infection as $\beta$ cells. $^{44}$

This study has demonstrated for the first time that ERK MAPK is involved in the mechanism of CX3CL1 gene transcription and subsequently, secretion of the gene product. There was a previous report that TNF- $\alpha$, IL- $1 \beta$, LPS, and ethanol-activated ERK in PSCs, ${ }^{33}$ but this study has revealed for the first time that poly $(\mathrm{I}: \mathrm{C})+\mathrm{Tfx}$ stimulation also induces phosphorylation. The previously known induction mechanisms of ERK were cell proliferation and secretion of cytokines and chemokines. According to the results of this study, ERK also induces chemokine activity of CX3CL1. A previous study has suggested that Stat-1 might be partially involved in the CX3CL1 gene transcription pathway, ${ }^{45}$ but only a few detailed studies have been conducted to date. This study has demonstrated for the first time that ERK MAPK has a central role in CX3CL1 gene transcription and that the ERK MAPK pathway has pathological significance in CX3CL1 expression in CP. Previous studies have reported 
a

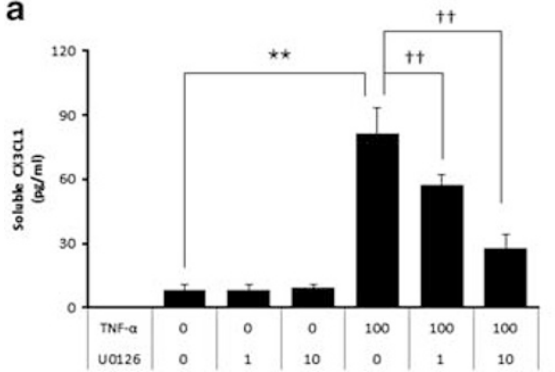

b
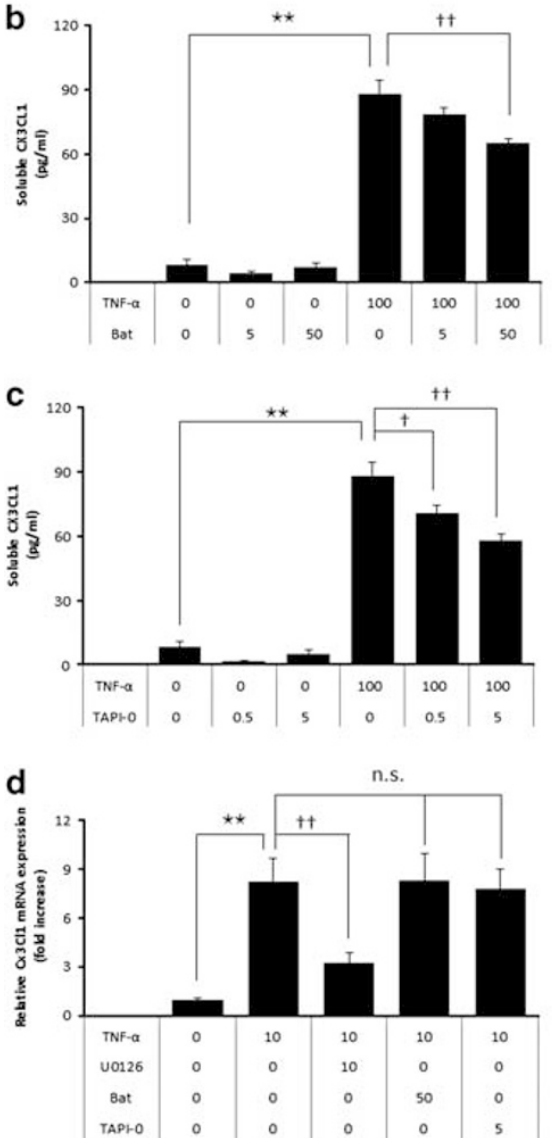
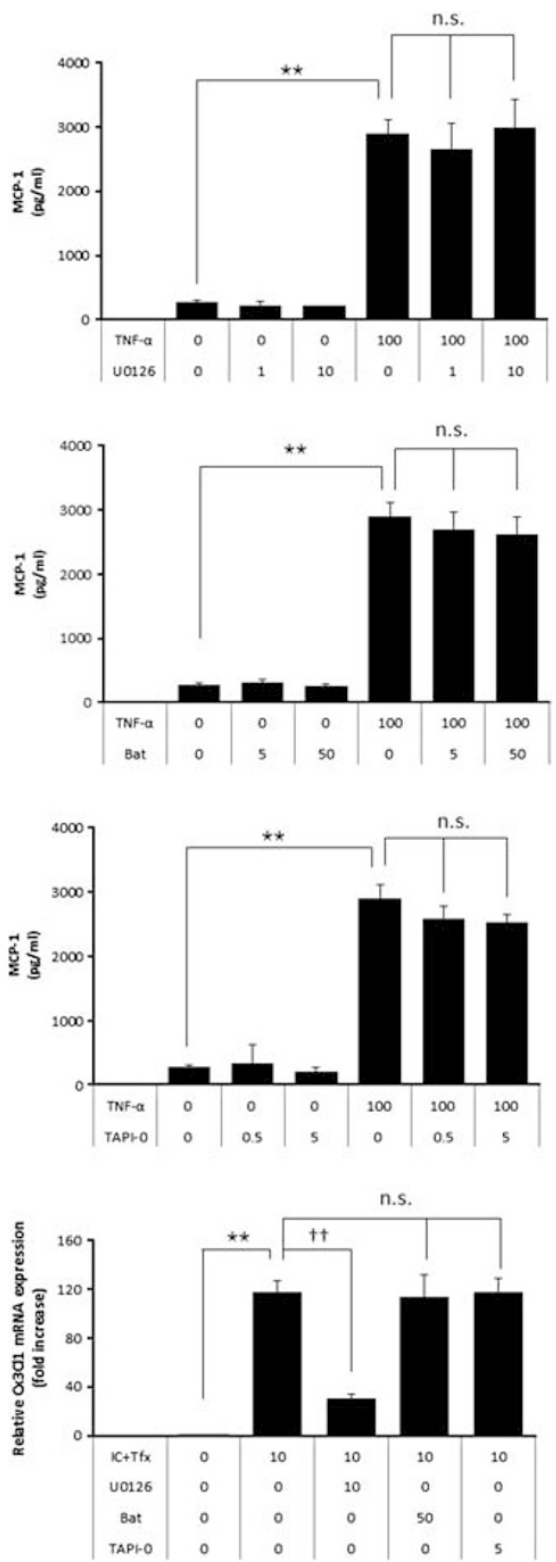

Figure 4 Signaling pathways required for CX3CL1 transcription and release. Pancreatic stellate cells (PSCs) were left untreated, or treated with tumor necrosis factor-alpha (TNF- $\alpha, 100 \mathrm{ng} / \mathrm{ml})(\mathbf{a}-\mathbf{c}),(\mathrm{TNF}-\alpha, 10 \mathrm{ng} / \mathrm{ml})(\mathbf{d})$, or polyinosinic-polycytidylic acid with Lipofectamine $2000(\mathrm{IC}+\mathrm{Tfx}, 10 \mu \mathrm{g} / \mathrm{ml})$ in the absence or presence of inhibitors of extracellular signal-regulated kinase (ERK), p38 mitogen-activated protein kinase, and sheddases for $24 \mathrm{~h}$ (a-c) or $6 \mathrm{~h}(\mathbf{d})$. (a-c) After $24 \mathrm{~h}$ of incubation, cell culture supernatants were harvested, and the levels of CX3CL1 and monocyte chemoattractant protein-1 (MCP-1) were determined by enzyme-linked immunosorbent assay (ELISA). We used U0126 (an inhibitor of the ERK pathway at 1-10 $\mu \mathrm{M}$ ), SB203580 (SB, an inhibitor of p38 MAPK at 25-100 $\mu \mathrm{g} / \mathrm{ml}$ ), batimastat (Bat, an inhibitor of matrix metalloproteinase at 5-50 $\mu \mathrm{m}$ ), and TAPI-0 (an inhibitor of a disintegrin and metalloprotease domain (ADAM) at $0.5-5 \mu \mathrm{g} / \mathrm{ml}$ ). (d) After $6 \mathrm{~h}$ of incubation, total RNA was prepared from treated PSCs and the expression of the CX3CL1 was assessed by real-time reverse transcription-polymerase chain reaction (RT-PCR; ${ }^{*},{ }^{\dagger} P<0.05 ;{ }^{*},{ }^{\dagger \dagger} P<0.01$; ns, not significant).

that ethanol and acetaldehyde also activate ERK and have confirmed that PMA induces ERK activation (data not shown), but the results of this study indicate that CX3CL1 gene expression is not induced solely by the abovementioned stimuli, because transcription factors other than ERK might be involved in the CX3CL1 transcription complex. CX3CL1 transcription was observed only when ethanol and PMA were administered during TNF- $\alpha$ and poly (I:C) Tfx stimulation, which suggests that other transcriptional factors, such as nuclear factor- $\kappa \mathrm{B}$ and interferon regulatory factor, might be involved. This suggests that alcohol consumption and environmental factors that activate PKC do not induce inflammation by themselves, but act as precipitating factors in the presence of other inflammation or infection. This finding is supported by the fact that excessive alcohol consumption is not the only 

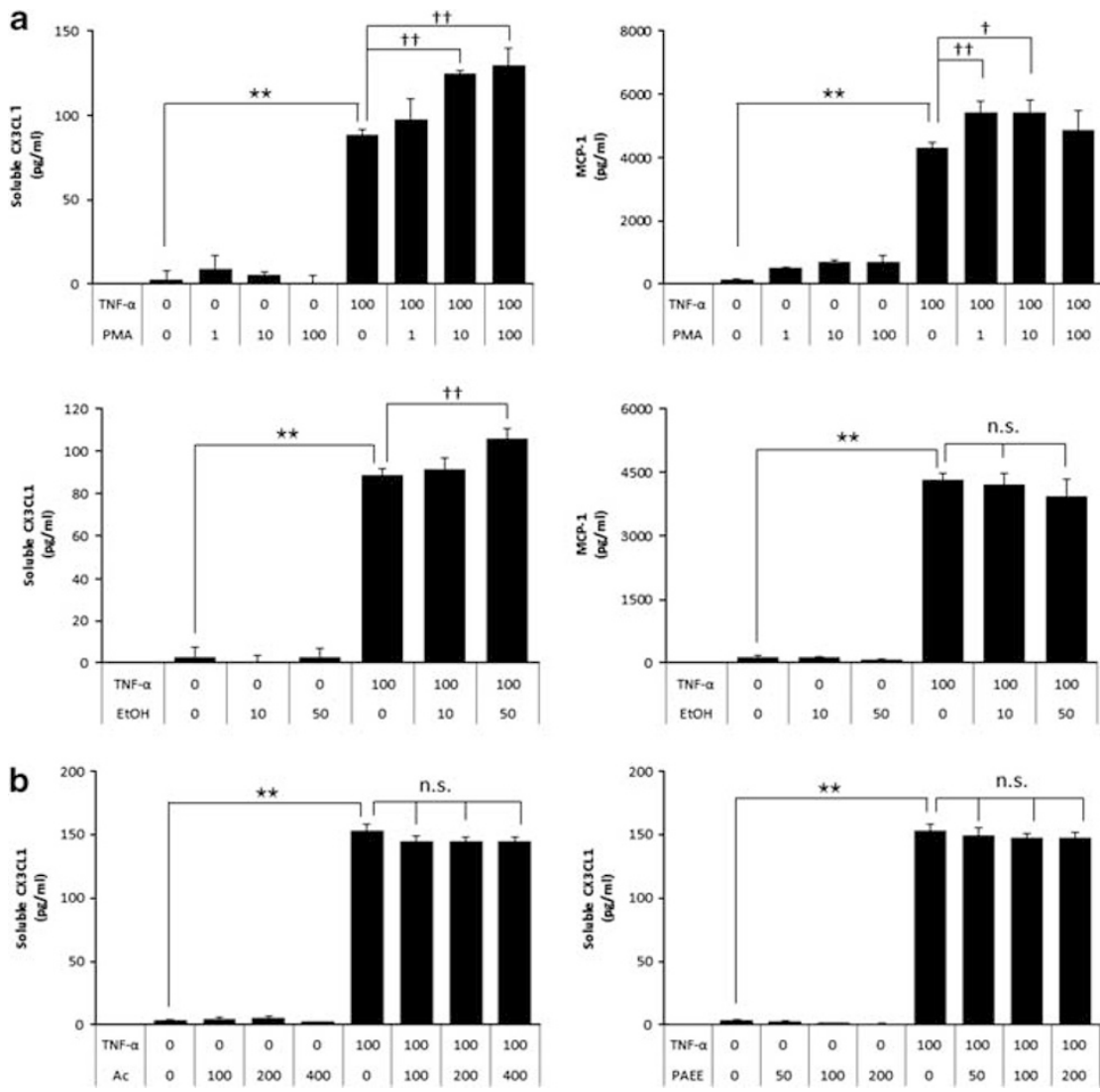

Figure 5 Ethanol and phorbol myristate acetate (PMA) synergistically increased CX3CL1 release. Pancreatic stellate cells (PSCs) were left untreated, or treated with tumor necrosis factor-alpha (TNF- $\alpha, 100 \mathrm{ng} / \mathrm{ml})$ in the absence or presence of PMA $(1-100 \mu \mathrm{g} / \mathrm{ml})$, ethanol (10-50 mM), acetaldehyde (Ac; $100-400 \mu \mathrm{M}$ ), or palmitic acid ethyl ester (PAEE; 50-200 $\mu \mathrm{M}$ ) for $24 \mathrm{~h}$. After incubation, cell culture supernatants were harvested, and the levels of CX3CL1 and monocyte chemoattractant protein-1 (MCP-1) were determined by ELISA $\left({ }^{*},{ }^{\dagger} P<0.05 ;{ }^{*},{ }^{\dagger \dagger} P<0.01\right.$; ns, not significant).

the cause of CP. It is probable that acetaldehyde and palmitic acid ethylester (PAEE) have endogenous and exogenous effects. Acetaldehyde is produced by acetaldehyde dehydrogenase $(\mathrm{ADH})$, the majority of which $(90 \%$ or more) is found in the liver, whereas PAEE is produced in the pancreas by pancreatic triglyceride lipase (PTL) and carboxyl ester lipase (CEL). The major effect of acetaldehyde on the pancreas is exogenous. There are also reports that PTL and CEL, which produce PAEE in the human stellate cells (PSCs), are not expressed at mRNA level, ${ }^{46}$ which suggests that the endogenous effects of both acetaldehyde and PAEE are smaller than the exogenous effects.

According to a study by Phillips et al, ${ }^{47} \mathrm{MMP}$ activation in stellate cells affects extracellular matrix hemostasis by matrix degradation. These authors performed their study using an ELISA assay for protein synthesized as a precursor, ${ }^{48}$ cleaved, and secreted into the supernatant, along with gelatin zymography for qualitative evaluation of the degradation of the gelatin matrix of MMP. This study included quantitative evaluation of the gene expression, precursor proteins, and protein expression after cleavage using real-time PCR and western blotting in order to examine enzyme activation. As the rate of activation of these enzymes was generally controlled, the activation could be correlated with the rate of expression in most cases. ${ }^{49}$ MMP-9 and ADAM17 are induced by inflammation, but MMP-2 is not. Stimulation by inflammation and infection did not change the expression of MMP-2 in PSCs, but it did increase the expression of MMP-9 and ADAM17, as indicated by real-time PCR results. ${ }^{49}$ This suggested that the MMP related to inflammation might be MMP-9 rather than MMP-2, although MMP-2 was involved in shedding of CX3CL1 in hepatic stellate cells. ${ }^{34}$ Such differences might occur because protease inhibitors such as batimastat inhibit other MMPs and ADAM or because the cell types were different. The activation of enzymes is caused by quantitative as well as qualitative changes in protein, and MMP is activated after cleavage of RXKR or RRKR sequences by furin in the Golgi. Accordingly, a qualitative change alone may influence the result. The precursor proteins of MMP-2 and MMP-9 in PSCs cannot be detected without stimulation. Furin is always activated in PSCs by a stimulant, and constitutive secretion of such proteins suggests that precursor 

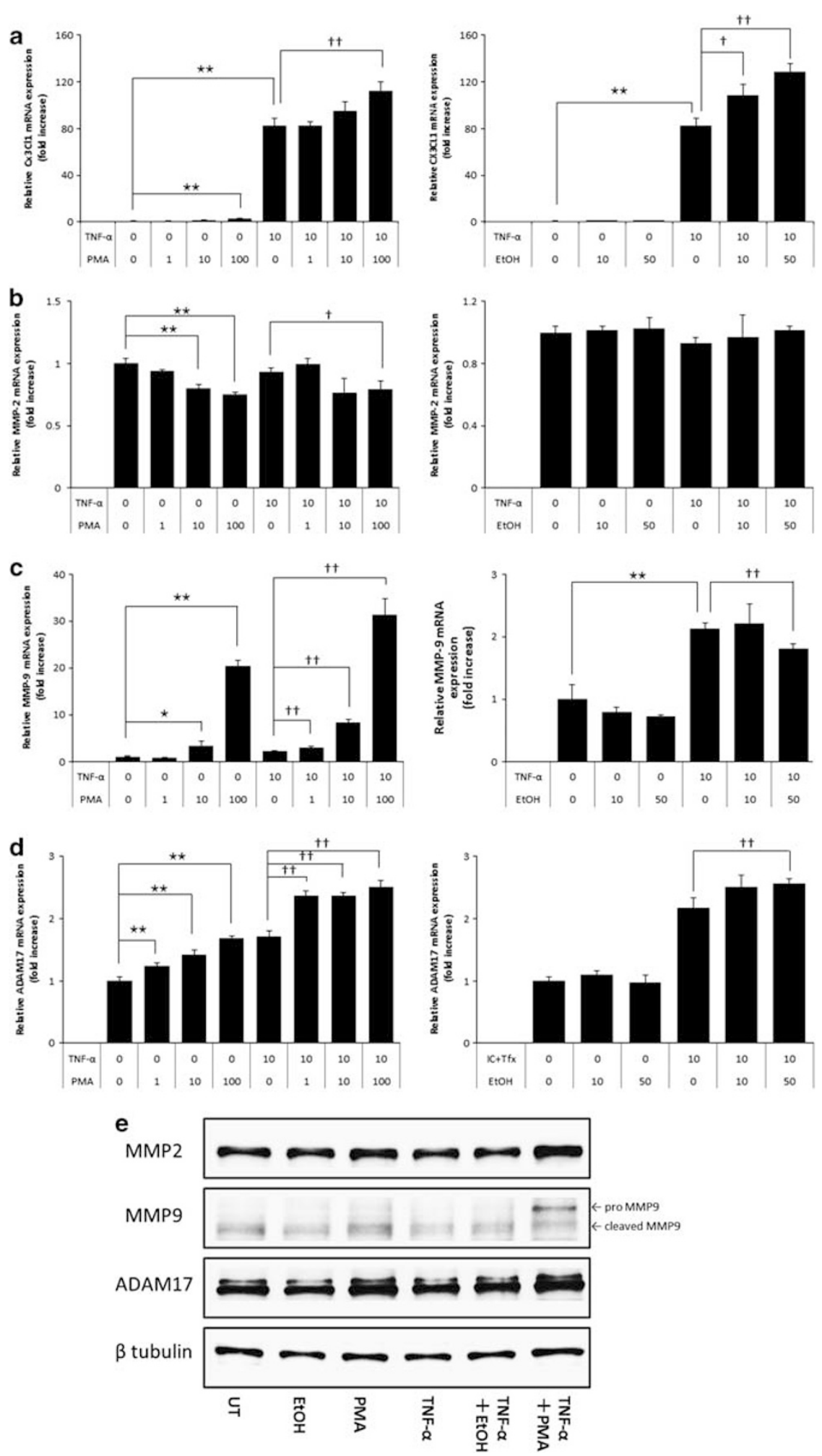

Figure 6 Extracellular signal-regulated kinase (ERK) and ADAM17 were required for synergistically increased CX3CL1 release induced by ethanol. Pancreatic stellate cells (PSCs) were left untreated (UT), or treated with tumor necrosis factor-alpha (TNF- $\alpha, 10 \mathrm{ng} / \mathrm{ml}$ ) in the absence or presence of phorbol myristate acetate (PMA, 1-100 $\mu \mathrm{g} / \mathrm{ml})$ or ethanol $(\mathrm{EtOH}, 10-50 \mathrm{~m} \mu \mathrm{m})$ for $6 \mathrm{~h}(\mathbf{a}-\mathbf{d})$. (a) After incubation, total RNA was prepared from treated PSCs and the expression of CX3CL1, (b) matrix metalloprotease (MMP)-2, (c) MMP-9, and (d) a disintegrin and metalloprotease domain (ADAM) 17 genes was assessed by real-time reverse transcription-polymerase chain reaction (RT-PCR). (e) Total cell lysates (approximately $50 \mu \mathrm{g}$ ) were prepared, and the level of MMP-9 was determined by western blotting $\left({ }^{*} \uparrow P<0.05 ;{ }^{*}, t^{\dagger \dagger} P<0.01\right)$. 


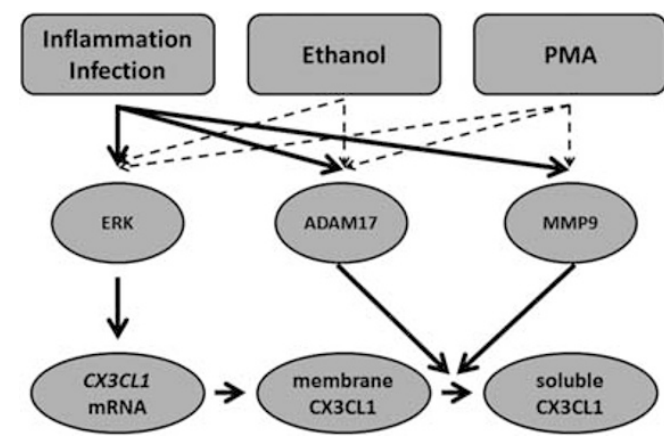

Figure 7 Mechanisms demonstrated in this study. If inflammation and infection are sustained or repeated, CX3CL1 mRNA is transcribed, leading to production of membrane-bound CX3CL1. Excess alcohol and metabolic state might synergistically perpetuate chronic inflammation in the pancreas by recruiting additional inflammatory cells. MMP, matrix metalloprotease; PMA, phorbol myristate acetate.

proteins of MMP-2 and MMP-9 would not have been detected by western blotting in this study. This result is the same as in the previously mentioned study by Phillips et al. ${ }^{47}$

Synergy of cell response by stimulation is the result of a multiplier response, which is produced by the generation of a single common molecular signal by multiple factors. Our study has revealed for the first time that secretion of a certain chemokine directly related to inflammation was synergistically promoted by ethanol. Furthermore, this study has demonstrated that known interactions with PMA were caused by synergistic CX3CL1 gene transcription and MMP-9 gene transcription associated with ERK activation. The precursor protein of MMP-9 observed in western blotting supported the synergy of transcription by TNF- $\alpha$ and PMA at the protein level. It is also possible that the mechanism of the interaction varies depending on ligand, which can be verified by examining a common downstream transcription factor. CX3CL1 was secreted alone by a few PMAs, in which PKC isozymes may have been involved, and it is very interesting that ethanol is a substrate of PKC.$^{50}$ The finding that both ethanol and acetaldehyde promoted MMP-2 secretion, but that acetaldehyde induced no synergetic secretion, supports the idea that MMP-9, instead of MMP-2, might be involved in the shedding of CX3CL1. The increased CX3CL1 concentration reported in the blood of drinkers probably reflects such mechanisms, ${ }^{17}$ and cessation of alcohol abuse as treatment would be expected to inhibit the synergistic secretion of CX3CL1. Withdrawal of alcohol has been associated with regression of LPS-induced pancreatic injury in alcohol-fed rats, where decreased serum CX3CL1 levels might be observed. ${ }^{51} \mathrm{PMA}$ is a ligand and activating factor of PKC, which is involved in diabetes and hypertension caused by an angiotensin II as well as alcohol consumption, which supports a role for lifestyle choices in the onset of some cases of CP.

In conclusion, this study has revealed a relationship between $\mathrm{CP}, \mathrm{CX} 3 \mathrm{CL} 1$, and sheddases in PSCs and it has demonstrated the presence of synergy of ethanol with PKC and other molecules in the CX3CL1 secretion mechanism. These findings should emphasize continued focus on the importance of cessation of alcohol abuse in patients with alcoholic CP.

Supplementary Information accompanies the paper on the Laboratory Investigation website (http://www.laboratoryinvestigation.org)

\section{ACKNOWLEDGEMENTS}

We appreciate for the technical supports from the Research Support Center, Graduate School of Medical Sciences, Kyushu University. This work was supported by a grant from the Ministry of Education, Culture, Sports, Science, and Technology, Japan (20590808, TI) and the Research Committee provided by the Ministry of Health, Labor, and Welfare Japan (50253448, TI).

\section{DISCLOSURE/CONFLICT OF INTEREST}

The authors declare no conflict of interest.

1. Gambill EE, Comfort MW, Baggenstoss $\mathrm{AH}$. Chronic relapsing pancreatitis; an analysis of 27 cases associated with disease of the biliary tract. Gastroenterology 1948;11:1-33.

2. Kloppel G, Maillet B. The morphological basis for the evolution of acute pancreatitis into chronic pancreatitis. Virchows Arch A Pathol Anat Histopathol 1992;420:1-4.

3. Apte MV, Haber PS, Applegate TL, et al. Periacinar stellate shaped cells in rat pancreas: Identification, isolation, and culture. Gut 1998;43:128-133.

4. Bachem MG, Schneider E, Gross H, et al. Identification, culture, and characterization of pancreatic stellate cells in rats and humans. Gastroenterology 1998;115:421-432.

5. McCarroll JA, Phillips PA, Park S, et al. Pancreatic stellate cell activation by ethanol and acetaldehyde: Is it mediated by the mitogen-activated protein kinase signaling pathway? Pancreas 2003;27:150-160.

6. Vonlaufen A, Xu Z, Daniel B, et al. Bacterial endotoxin: a trigger factor for alcoholic pancreatitis? evidence from a novel, physiologically relevant animal model. Gastroenterology 2007;133:1293-1303.

7. Masamune A, Kikuta K, Watanabe T, et al. Pancreatic stellate cells express toll-like receptors. J Gastroenterol 2008;43:352-362.

8. Morishita K, Shimizu K, Haruta I, et al. Engulfment of gram-positive bacteria by pancreatic stellate cells in pancreatic fibrosis. Pancreas 2010;39:1002-1007.

9. Nakamura $\mathrm{T}$, Ito $\mathrm{T}$, Oono $\mathrm{T}$, et al. Bacterial DNA promotes proliferation of rat pancreatic stellate cells thorough Toll-like receptor 9: potential mechanisms for bacterially induced fibrosis. Pancreas 2011;40: 823-831.

10. Andoh A, Takaya $H$, Saotome $T$, et al. Cytokine regulation of chemokine (IL-8, MCP-1, and RANTES) gene expression in human pancreatic periacinar myofibroblasts. Gastroenterology 2000;119: 211-219.

11. Ito T. Can measurement of chemokines become useful biological and functional markers of early-stage chronic pancreatitis? J Gastroenterol 2007;42(Suppl 17):72-77.

12. Iwamoto $\mathrm{T}$, Okamoto $\mathrm{H}$, Toyama $\mathrm{Y}$, et al. Molecular aspects of rheumatoid arthritis: Chemokines in the joints of patients. FEBS J 2008;275:4448-4455.

13. Zhao HF, Ito T, Gibo J, et al. Anti-monocyte chemoattractant protein 1 gene therapy attenuates experimental chronic pancreatitis induced by dibutyltin dichloride in rats. Gut 2005;54:1759-1767.

14. Bazan JF, Bacon KB, Hardiman G, et al. A new class of membranebound chemokine with a CX3C motif. Nature 1997;385:640-644.

15. Baggiolini $M$, Dewald B, Moser B. Interleukin-8 and related chemotactic cytokines-CXC and CC chemokines. Adv Immunol 1994;55:97-179.

16. Koch AE. Chemokines and their receptors in rheumatoid arthritis: future targets? Arthritis Rheum 2005;52:710-721.

17. Yasuda M, Ito T, Oono T, et al. Fractalkine and TGF-beta1 levels reflect the severity of chronic pancreatitis in humans. World J Gastroenterol 2008; 14:6488-6495. 
18. Ceyhan GO, Deucker S, Demir IE, et al. Neural fractalkine expression is closely linked to pain and pancreatic neuritis in human chronic pancreatitis. Lab Invest 2009:89:347-361.

19. Ruth JH, Volin MV, Haines 3rd GK, et al. Fractalkine, a novel chemokine in rheumatoid arthritis and in rat adjuvant-induced arthritis. Arthritis Rheum 2001;44:1568-1581.

20. Lesnik P, Haskell CA, Charo IF. Decreased atherosclerosis in CX3CR1-/mice reveals a role for fractalkine in atherogenesis. J Clin Invest 2003;111:333-340.

21. Combadiere C, Potteaux S, Gao JL, et al. Decreased atherosclerotic lesion formation in CX3CR1/apolipoprotein E double knockout mice. Circulation 2003:107:1009-1016.

22. Ikejima $\mathrm{H}$, Imanishi T, Tsujioka $\mathrm{H}$, et al. Upregulation of fractalkine and its receptor, CX3CR1, is associated with coronary plaque rupture in patients with unstable angina pectoris. Circ J 2010;74:337-345.

23. Cockwell P, Chakravorty SJ, Girdlestone J, et al. Fractalkine expression in human renal inflammation. J Pathol 2002;196:85-90.

24. Nakatani $\mathrm{K}$, Yoshimoto $\mathrm{S}$, Iwano $\mathrm{M}$, et al. Fractalkine expression and $\mathrm{CD} 16+$ monocyte accumulation in glomerular lesions: association with their severity and diversity in lupus models. Am J Physiol Renal Physiol 2010;299:F207-F216.

25. Combadiere C, Salzwedel K, Smith ED, et al. Identification of CX3CR1. A chemotactic receptor for the human $\mathrm{CX} 3 \mathrm{C}$ chemokine fractalkine and a fusion coreceptor for HIV-1. J Biol Chem 1998;273:23799-23804.

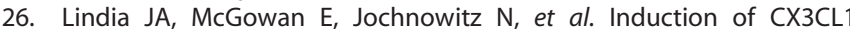
expression in astrocytes and CX3CR1 in microglia in the spinal cord of a rat model of neuropathic pain. J Pain 2005:6:434-438.

27. Verge GM, Milligan ED, Maier SF, et al. Fractalkine (CX3CL1) and fractalkine receptor (CX3CR1) distribution in spinal cord and dorsal root ganglia under basal and neuropathic pain conditions. Eur J Neurosci 2004:20:1150-1160.

28. Jones BA, Beamer M, Ahmed S. Fractalkine/CX3CL1: a potential new target for inflammatory diseases. Mol Interv 2010;10:263-270.

29. D'Haese JG, Demir IE, Friess H, et al. Fractalkine/CX3CR1: why a single chemokine-receptor duo bears a major and unique therapeutic potential. Expert Opin Ther Targets 2010;14:207-219.

30. Mori Y, Yokoyama J, Nishimura M, et al. Diabetic strain (WBN/Kob) of rat characterized by endocrine-exocrine pancreatic impairment due to distinct fibrosis. Pancreas 1990;5:452-459.

31. Nakamura $\mathrm{T}$, Ito $\mathrm{T}$, Igarashi $\mathrm{H}$, et al. Cytosolic double-stranded DNA as a damage-associated molecular pattern induces the inflammatory response in rat pancreatic stellate cells: a plausible mechanism for tissue injury-associated pancreatitis. Int J Inflam 2012:2012:504128.

32. Dogusan Z, Garcia M, Flamez D, et al. Double-stranded RNA induces pancreatic beta-cell apoptosis by activation of the toll-like receptor 3 and interferon regulatory factor 3 pathways. Diabetes 2008;57: 1236-1245.

33. Masamune A, Shimosegawa T. Signal transduction in pancreatic stellate cells. J Gastroenterol 2009;44:249-260.

34. Bourd-Boittin $\mathrm{K}$, Basset $\mathrm{L}$, Bonnier $\mathrm{D}$, et al. CX3CL1/fractalkine shedding by human hepatic stellate cells: contribution to chronic inflammation in the liver. J Cell Mol Med 2009;13:1526-1535.
35. Das J, Pany S, Rahman GM, et al. PKC epsilon has an alcohol-binding site in its second cysteine-rich regulatory domain. Biochem $J$ 2009:421:405-413.

36. Isse $\mathrm{K}$, Harada $\mathrm{K}$, Zen $\mathrm{Y}$, et al. Fractalkine and CX3CR1 are involved in the recruitment of intraepithelial lymphocytes of intrahepatic bile ducts. Hepatology 2005;41:506-516.

37. Wasmuth $\mathrm{HE}$, Zaldivar $\mathrm{MM}$, Berres $\mathrm{M}$-, et al. The fractalkine receptor CX3CR1 is involved in liver fibrosis due to chronic hepatitis C infection. J Hepatol 2008;48:208-215.

38. Apte MV, Wilson JS. Stellate cell activation in alcoholic pancreatitis Pancreas 2003;27:316-320.

39. Mews $P$, Phillips $P$, Fahmy $R$, et al. Pancreatic stellate cells respond to inflammatory cytokines: Potential role in chronic pancreatitis. Gut 2002:50:535-541.

40. Chandrasekar B, Mummidi S, Perla RP, et al. Fractalkine (CX3CL1) stimulated by nuclear factor $\kappa \mathrm{B}$ (NF- $\kappa \mathrm{B})$-dependent inflammatory signals induces aortic smooth muscle cell proliferation through an autocrine pathway. Biochem J 2003:373:547-558.

41. Perros $F$, Dorfmüller $P$, Souza $R$, et al. Fractalkine-induced smooth muscle cell proliferation in pulmonary hypertension. Eur Respir J 2007;29:937-943.

42. White $\mathrm{GE}$, Tan $\mathrm{TC}$, John $\mathrm{AE}$, et al. Fractalkine has anti-apoptotic and proliferative effects on human vascular smooth muscle cells via epidermal growth factor receptor signalling. Cardiovasc Res 2010;85:825-835.

43. Ludwig A, Berkhout $\mathrm{T}$, Moores $\mathrm{K}$, et al. Fractalkine is expressed by smooth muscle cells in response to IFN- $\gamma$ and TNF- $\alpha$ and is modulated by metalloproteinase activity. J Immunol 2002;168:604-612.

44. Garcia M, Dogusan Z, Moore F, et al. Regulation and function of the cytosolic viral RNA sensor RIG-I in pancreatic beta cells. Biochim Biophys Acta 2009;1793:1768-1775.

45. Isozaki T, Otsuka K, Sato M, et al. Synergistic induction of CX3CL1 by interleukin-1 beta and interferon-gamma in human lung fibroblasts: involvement of signal transducer and activator of transcription 1 signaling pathways. Transl Res 2011;157:64-70.

46. Masamune A, Satoh A, Watanabe T, et al. Effects of ethanol and its metabolites on human pancreatic stellate cells. Dig Dis Sci 2010;55:204-211.

47. Phillips PA, McCarroll JA, Park S, et al. Rat pancreatic stellate cells secrete matrix metalloproteinases: implications for extracellular matrix turnover. Gut 2003;52:275-282.

48. Harper $\mathrm{E}$, Bloch $\mathrm{KJ}$, Gross J. The zymogen of tadpole collagenase. Biochemistry 1971;10:3035-3041

49. Ra HJ, Parks WC. Control of matrix metalloproteinase catalytic activity. Matrix Biol 2007;26:587-596.

50. Hundle B, McMahon T, Dadgar J, et al. An inhibitory fragment derived from protein kinase $C \varepsilon$ prevents enhancement of nerve growth factor responses by ethanol and phorbol esters. J Biol Chem 1997:272:15028-15035.

51. Vonlaufen A, Phillips PA, Xu Z, et al. Withdrawal of alcohol promotes regression while continued alcohol intake promotes persistence of LPS-induced pancreatic injury in alcohol-fed rats. Gut 2011;60: 238-246. 